\title{
An Ethnopharmacognostic Approach to the Search for Immunomodulators of Plant Origin
}

\author{
R. P. Labadie ${ }^{1,3,4}$, J. M. van der Nat ${ }^{1}$, J. M. Simons ${ }^{1}$, B. H. Kroes ${ }^{1}$, S. Kosasi ${ }^{1}$, A. J. J. van den Berg ${ }^{1}$, \\ L. A. 't Hart', W. G. van der Sluis', A. Abeysekera' ${ }^{2}$, A. Bamunuarachchi', and K. T. D. De Silva ${ }^{2}$ \\ ${ }^{1}$ Department of Pharmacognosy, Faculty of Pharmacy, University of Utrecht, Catharijnesingel 60, 3511 GH Utrecht, \\ The Netherlands \\ ${ }^{2}$ Department of Chemistry, University of Sri Jayewardenepura, Nugegoda, Sri Lanka \\ ${ }^{3}$ Address for correspondence \\ ${ }^{4}$ Plenary Lecture at the $36^{\text {th }}$ Annual Congress of the Society for Medicinal Plant Research, Freiburg, 12. to 16.9.1988
}

Received: November 21, 1988

\begin{abstract}
The search for immunomodulating plant constituents through basic and field inquiries into the literature and practices of traditional Indian medicine is treated. The strategy of data collecting proceeds through aspects of an ethnobotanical, an ethnopharmaceutical, an ethnopharmacological, and an ethnomedical nature. In the experimental immunopharmacognostic phase, immunomodulatory compounds are isolated and purified through actionguided fractionation procedures. The results described here refer to activities found on human complement activation and on PMN leucocytes activation. The immunomodulating plant compounds included in this report were isolated from Azadirachta indica bark, Woodfordia fructicosa flowers, Picrorhiza kurroa roots, and Jatropha multifida latex.
\end{abstract}

\section{Introduction}

The ultimate biomedical goal of pharmacognosy is to contribute to the causal and hence rational relationships between the chemical constituents of medicinal plant preparations and the biological and therapeutic effects they generate. To operate towards such an objective, a series of basic and applied fields of knowledge has to be covered functionally. One of them is ethnopharmacognosy.

Recently a monograph on cannabinoids as therapeutic agents appeared (1). That the first chapter deals with the pharmacohistory of Cannabis sativa is very meaningful for fresh approaches in the development of new plant drugs (1).

Referring to Tschirch's monumental handbook, in which more than 500 pages have been devoted to "Pharmakohistoria", Mechoulam (1986) states that "pharmacohistory is a somewhat neglected corner of knowledge and deserves resurrection". The statement reflects the factual situation that pharmacognosy, in view of its modern auxiliary disciplines (chemotaxonomy, phytochemistry, biosynthesis, pharmacology), has become an almost exclusively laboratoryoriented discipline. Historically, however, the medicinal plant product (or in a broader sense the natural product) as subject matter of pharmacognosy was directly and closely connected with the traditional knowledge of its use. Scientific advancement within medicinal plant research proceeded mainly with respect to the biological and the chemical nature of plant drugs. Neglect of the scientific study of traditional medicinal data in connection with botanical and chemical aspects, drifted this science away from a very rich source of information. This situation and the necessity for a less random search for active components in plants certainly contributed to the need felt in scientific circles to explore traditional knowledge of medicinal products used in ethnic groups (2-5). The terms ethnopharmacology (2) and ethnopharmacognosy (6) were proposed to reflect the ethnologically oriented approach in scientific exploration of traditionally used natural products. This approach involves the pharmacognosist into an interdisciplinary setting including anthropology, (medical) sociology, linguistics, and philology besides the usual natural sciences and medicine. It should be realized that the pharmacognosist involved in ethnopharmacognostic research is bound to collect data in field work, i.e. in the actuality of users, producers, prescribers, and the practice of traditional medicines and therapies, besides the study of ancient and modern literature relevant to traditional and folkloric practices $(6-8)$.

The geographical location for ethnopharmacognostic field work is, in principle, a matter of choice. Other factors of scientific, economic, and political nature, however, may influence this choice. In fact, any ethnic society which has preserved and retained some or an extensive part of its traditional medicinal knowledge and which is being applied in practice, is a candidate for ethnopharmacognostic research.

Proper evaluation of literature and field work data provides a set of plants which deserves priority to be investigated experimentally for a selected biological activity or efficacy against a selected disorder or disease.

Approach and Strot,

Basically, emp cal ob itions on pharmaco-medical properties of natu. ${ }^{1}$ pr.ducts used within the concepts of the different systems of traniunum inedicine can be

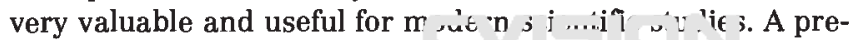
requisite, however, is that the urta are viewed and analysed 
within the traditional concepts they fit in. An ethnopharmacognostic inquiry is designed to meet this basic requirement. Such an approach allows a better chance to arrive at:

1. the plant species which deserve priority in the investigation;

2 . the type of medicinal preparation which contains and conditions, respectively, the active constituents;

3. a more appropriate basis for the selection of relevant pharmacological tests;

4. the proper pharmaco-therapeutic category or subcategory, or indications of medical importance.

The strategy which is followed to collect relevant data comprises a literature study stage and one or more field work study stages. The literature inquiry is focused on conceptual aspects of the traditional system under consideration and a survey on specific remedies and medicinal plants which have been described to be used in cases of the disorders or biological activity under consideration. The field inquiry evaluates the current status and views on the practice of the medical system and on data in classical texts. It is directed along four integrated question areas:

\section{Questions of an ethnobotanical nature}

These aim at full consistency between vernacular plant names (and descriptions) on one hand and the botanical identity of the species or variety under consideration on the other hand. Problems concerning synonymy, the fact that different plant species are known under the same vernacular name, wrong botanical determinations, substitutions, adulterations, etc. are dealt with.

\section{Questions of an ethnopharmaceutical nature}

These aim at finding out the nature and quality aspects and considerations of the traditional medicinal preparation from crude plant material. Technical and quality considerations concerning the conditions of the plant material, its collection, its conservation, its pretreatment, and its extraction and dosage form are dealt with.

\section{Questions of an ethnopharmacological nature}

These are concerned with the traditional claims of biological or therapeutical action(s). Their aim is to get a clear picture or at least an impression of the site of action and the nature of the claimed or expected effect.

\section{Questions of an ethnomedical nature}

These are concerned with the medical applications of the plant drugs under consideration. This inquiry includes the pathological conditions, or the diseases (according to the concepts of the medicinal system under study), for which the plant drug is indicated. Curative as well as preventive applications of the traditional drug are considered and surveyed.

Covering these question areas, different mo ifications of a questionnaire are used to consult and interview professional prescribers, producers, and users of the traditional drugs. Evaluation of data obtained in the field inqu' $y$ y and literature study leads to the best possible hypothesis $\mathrm{tnr}$ laboratory experimentation.

\section{Immunomodulation and Traditional Medicine}

The decision to focus on plant constituents which modulate immune responses raises the question whether there is a conceptual basis in the traditional medicine under study for such a biological activity. In other words, do the concepts of pathogenesis and therapeutic methods on which the traditional system is based offer a relevant approach.

In the following this question is discussed with respect to Ayurveda, an important system of traditional medicine in India and Sri Lanka. The terms immune system and immunodolulation in the sense that they are used in modern science are lacking in Ayurveda.

The basic function of the immune system is a detect and destroy of the non-self, and thus a defence mechanism. The system works throughout the entire body through an intricate regulation of humoral and cellular factors. Functioning of the immune system is interconnected with the central nervous system and the endocrine system (9). Its protective task, starting with the recognition of non-self bodies and substances, puts the immune system in a vital position between a healthy and a diseased state of a host.

According to Ayurveda, common causes of diseases may be put in terms of contact with environmental factors, psychological factors (i.e. the unbalance between self-control and temptations) and ageing. The latter is inevitable and the second cause can only be avoided by "scrupulously puritan patterns" of living. Ayurveda claims to be able to avoid the first cause successfully. Present professionals focus their efforts in health care especially on environmental causes of disease (10). At the basis of conceptual notions on requirements for a healthy condition and the causes of pathogenesis lies the Tridosha theory. These three doshas represent causative principles in the human body. Vata-dosha represents functions of movement or propulsion (e.g., breathing, beating of the heart, common actions like lifting, catching, throwing etc., but also swallowing, vomiting, and excretion); pitta-dosha represents the functions of interchange and conversion (e.g. the conversion of food substances to various body constituents, the perception of knowledge and memory, the conversion which happens in liver, spleen, the haemopoeitic pool); kapha-dosha represents interlinking functions and constituents of the body (e.g. involving growth processes, secretory processes, etc.). When the functions controlled by the doshas are in balance in a person, a healthy condition exists. Otherwise the person suffers from a disease. As a consequence of these concepts, prevention of disease aims at maintenance of the balance between the three doshas and therapy aims at restoration of the balance. Specifically, the maintenance of the body functions is understood in terms of movement of fluids or secretions to organs and tissues in the trunk and away from the trunk to head and limbs.

A variety of inflammatory conditions is vilsidered in Ayurveda to be connected with disturbances in the $\mathrm{r}^{--}$ement of body fluids or secretions.

A series of physiological and therapeutic termo are connected with processes, actions, and mechanisms in $1 \cdots-1:$ pir 
The term Koshthagati, for example, refers to factors which are able to cause a central pull or propulsion of movement towards the lumen of hollow organs (e.g. the intestinal tract). In this relation, certain "substances" (e.g. "fatty" substances) are described to have a specific secretogogue action on particular hollow organs. These "substances" in combination with, for example, warmth treatments are used to move away the products of morbidity by stimulation of circulation, and inflammations may get suppressed. The term Vridhi refers to flow and effect of propagating secretions to hollow organs, and the term Abhishyandana refers to induction of moving products of morbidity away by circulation, and suppressing inflammation. The process by which suppression of morbid components is induced to minimize tissue damage is termed paka. The drainage of suppuration and cleansing of the (inflamed) system is termed srotomukhavishodhana. Treatments using medicinal preparations and other types of medication and diets are designed to achieve the above-mentioned effects. Important ayurvedic terms of treatment programmes in this respect are Pancha Karma and Rasayana. The former comprises a programme of treatments aiming at purifying the entire body from morbid substances. The latter refers to a treatment in which the body constituents are prepared to adapt a selective tissue endowment programme. In this respect another Ayurveda term, Vata nigraha, is of interest. This term refers to "the involvement of the mind of a person in the total management of protective and purifying processes" in the body. This indicates a general awareness in Ayurveda. of a functional interconnection between the (central) nervous system and protective processes in the body. It is obvious that the concepts of pathogenesis in Ayurveda incorporates elements which can be recognised as an awareness of phenomena which can be expressed in terms of a self-protective system in human beings and its modulation by therapeutics, diets and treatments (10). With these fundamental principles and terms of pathogenesis and therapy in mind, a field inquiry was set up and carried out in Sri Lanka.

A questionnaire was used to consult professionals, producers and users on the therapeutic means applied in disorders and diseases (in terms of Ayurveda) which can reasonably be associated with dysfunctions of immune factors. These interviews covered questions on skin diseases, inflammatory and rheumatic conditions, infections, wounds, burns, and the therapeutic preparations and treatments used to vitalize, strengthen, and stimulate body functions, to "purify" the blood, tissues, and organs. The questionnaire also included questions on plants and preparations used as tonics and generally in maintaining health and in prevention of disease, while the position, the role, and the significance of plant ingredients in diets was investigated.

\section{Immunopharmacognosy (Experimental Phase)}

Following the field inquiry, an experimental phase is entered and laboratory research is carried out using the results of the ethnopharmacognostic inquiry as guidelines. Since immunomodulatory activity of plant constituents and medicinal plant preparations is under study, this experimental field of research has been termed immunopharmacognosy. In fact the plant species selected are firstly screened for immunomodulative activity in vitro. The part of the plant material, its treatment and condition, and the type of crude extract preparation taken into the screening programme is determined by the nature of the traditional preparation under consideration. Since immunomodulative activity may be expressed on quite different factors of the immune system, a battery of assays are included in the screening phase. This strategy allows detection of selective action already in an early stage. On the basis of activity found in the screen tests, an action-guided fractionation and purification of crude extracts is conducted until one or more single active compounds have been isolated. A basic point of attention in the course of this procedure is the steady increase of activity on a weight basis, a strong indication of enrichment of the active constituent(s). After the identification and the structural elucidation of the active compounds the mechanism of action is studied. In this stage attention is given to the questions of specificity, selectivity, and toxicity. The latter is being focused on the normal functionality of cells involved in the immune response. With respect to the immunomodulative activity found the pharmacognosist, being familiar with the accumulation and distribution of compounds similar and structurally related to the active compounds, may perform structure/activity relationship studies. At this point, it is significant to point out that the search for the rationale and innovative elements does not and should not stop when one has found one or more active constituents in the plant materials under consideration. In particular, an ethnopharmacognostic approach allows a further rationalisation when traditional preparation methods, their technological principles, and conditions are studied carefully, critically but unprejudiced. With respect to chemical changes during the preparation procedure and their consequences for the biological activity, significant and important findings can be done. Equally significant and interesting results with respect to the bio-availability of active constituents in traditional preparations deserve attention.

The relation between humoral and cellular factors and processes in the functioning of the immune system is a complicated one.

On the basis of the "non-self recognition and destroy" function immunofactors can be distinguished in antigen non-specific and antigen specific humoral and cellular factors (Fig. 1). It is intended within the scope of this paper to focus on modulative activity regarding the antigen non-specific immune response factors, complement and PMN leucocytes.

As Fig. 1 indicates, the factors of the antigen non-specific immune response show functional interactions with those of antigen specific immune response, and both are closely connected with inflammatory conditions. However, the activation of both complement and polymorphonuclear leucocytes (PMN) are in particular involved in acute inflammation, while T-lymphocytes, lymphokines, and macrophages are particularly involved with chronic inflammatory responses and conditions (11). It is obvious that modulation of complement activation and PMN activation will indirectly influence also chronic inflammation.

-umplement comprises nine pro-enzymes (C1 to C9) presf $\Delta$ in ser - When activated, at least seventeen proteins are $\mathrm{ft}$ ned ou nine non-active factors in a cascade of events. 


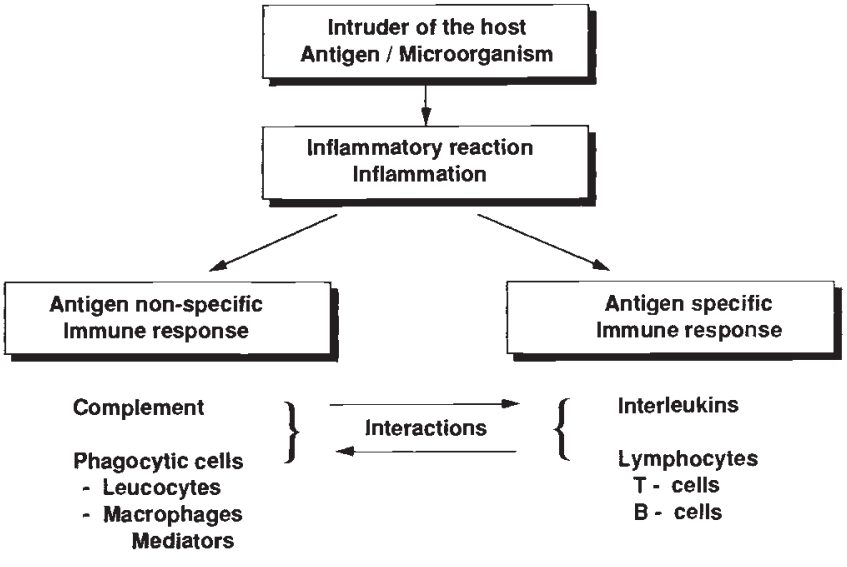

Fig. 1 Differentiation of immune responses.

The involvement of the activated complement in animals to inflammatory responses and noxious stimuli may include: increased capillary (vascular) permeability, smooth muscle contraction (factors C3a and C5a), mast cell degranulation, localization of complexes in germinal centres, opsonization and phagocytosis of bacteria, neutrophil activation and chemotaxis, lysis of bacteria and other foreign (to the host) cells. There are two major pathways of complement activation known as the classical pathway and the alternative pathway.

The former is activated by immune complexes of antigen and antibodies (IgG or $\operatorname{IgM}$ ), the latter is activated by bacteria or other foreign (to the host) cells, or a wide variety of substances introduced into the serum. These include complex polysaccharides (e.g. inulin, zymosan), lipopolysaccharides (e.g. bacterial endotoxins), and immune complexes containing immunoglobulins of the IgA or IgD classes that cannot activate the classical pathway. Both activation pathways lead to the same terminal phase (C5-C9) of the complement cascade resulting in lysis of the target cell foreign to the host of the complement system $(12-14)$. The results of modulation studies on complement activation described in this paper are based on assays which use the cytolytic capacity of activated complement as a measurable criterium (15).

As pointed out, PMN leucocytes are particularly involved in acute inflammatory responses. Their influx into the affected tissue spaces is induced by complement cascade factors inducing chemotaxis and increased capillary permeability. At the site of affection they are activated by antigenantibody-complement complexes (immune complexes). In the activated state, PMN leucocytes are able to perform phagocytosis. Under normal conditions the agents (immune complexes) which cause inflammation are destroyed by hydrolytic enzymes in the phagolysosome, and by metabolically generated reactive oxygen intermediates (ROI), i.e. oxygen radicals $\left[\mathrm{O}_{2}^{-}\right.$(superoxide anion); $\mathrm{H}_{2} \mathrm{O}_{2}$ (hydrogen peroxide); $\cdot \mathrm{OH}$ (hydroxyl radical)]. As part of this so-called respiratory burst, also hypohalite ions are produced by oxidation of ubiquitous halide ions with hydrogen peroxide (16). A number of oxidizing enzymes, present in azuriphilic granules, are associated with the catalysis of the formation of these highly reactive and hence destructive biological radicals and ions. In the case that the acute immune response rids the host of the immune complexes that induced inflammation, then repair and regeneration follows at the affected site. If not, the influx of PMN and serum proteins continues, which leads to cell death and tissue injury. Many pathological conditions arise through derailed immune responses to acute and chronic inflammatory agents. The assays applied to study modulation of PMN leucocyte activation, within the scope of this paper, are based on the ability of these cells to generate reactive oxygen radicals on activation with

\begin{tabular}{|c|c|c|c|c|}
\hline \multirow{2}{*}{$\begin{array}{l}\text { Plant species, (plant part) } \\
\text { and Sinhalese name }\end{array}$} & \multirow[t]{2}{*}{ Plant family } & \multicolumn{2}{|c|}{$\begin{array}{l}\text { Anti-complementary activity } \\
\text { Percentage of inhibition on: }\end{array}$} & $\begin{array}{l}\text { complement } \\
\text { of some me }\end{array}$ \\
\hline & & $\begin{array}{c}\text { Alternative } \\
\text { Pathway in } \\
\mathrm{AP}_{50 \text { values }} \\
c=500 \mu \mathrm{g} / 300 \mu \mathrm{l}\end{array}$ & $\begin{array}{c}\text { Classical } \\
\text { Pathway } \\
\mathrm{CH}_{50} \text { values } \\
c=75 \mu \mathrm{g} / 300 \mu \mathrm{l}\end{array}$ & ethnopharm \\
\hline $\begin{array}{l}\text { Adhatoda vasica } \\
\text { (root bark), Adatoda }\end{array}$ & Acanthaceae & 20.5 & 39.7 & \\
\hline $\begin{array}{l}\text { Aegle marmelos } \\
\text { (fruit pulp), Beli }\end{array}$ & Rutaceae & 37.6 & n.s. & \\
\hline $\begin{array}{c}\text { Andrographis panicu- } \\
\text { lata (whole plant) } \\
\text { Hin-Binkohomba }\end{array}$ & Acanthaceae & n.s. & 61.1 & \\
\hline $\begin{array}{l}\text { Asparagus falcata } \\
\text { (tuberous roots), } \\
\text { Hathawariya }\end{array}$ & Liliaceae & n.s. & 100 & \\
\hline $\begin{array}{l}\text { Azadirachta indica } \\
\text { (bark), Kohomba }\end{array}$ & Meliaceae & 38.4 & 100 & \\
\hline $\begin{array}{l}\text { Centella asiatica } \\
\text { (whole plant), Gutokola }\end{array}$ & Umbelliferae & 34.7 & 27.6 & \\
\hline $\begin{array}{l}\text { Munronia pumila (whole } \\
\text { plant), Bin-kohomba }\end{array}$ & Meliaceae & n.s. & 49.9 & \\
\hline $\begin{array}{l}\text { Picrorhiza kurroa (roots) } \\
\text { Katukarosana }\end{array}$ & $\begin{array}{l}\text { Scrophularia- } \\
\text { ceae }\end{array}$ & 30.2 & .3 & \\
\hline $\begin{array}{l}\text { Piper longum (fruit spikes) } \\
\text { Tippili }\end{array}$ & Piperaceae & n.s. & & \\
\hline $\begin{array}{l}\text { Vernonia cinerea (whole } \\
\text { plant), Monara-kudimbiya }\end{array}$ & Compositae & 100 & $\ln n$ & \\
\hline
\end{tabular}


zymosan, PMA (phorbol myristate acetate), or other inducers. The oxygen radical production is measured by means of a luminometer. The method is based on the measuring of chemiluminescence which is produced when the oxygen radicals excite compounds like luminol present in the test medium (17). Under the circumstances of an inhibitory plant constituent, the phagocytic capacity of the PMN leucocytes is tested in a separate assay (18).

\section{Results and Discussion}

It should be mentioned here that the series of plant species which came out of the ethnopharmacognostic inquiry, hence supposedly to be prior candidates for immunomodulative properties, belong to many and quite different plant families.

In the initial screening the effect on complement activation was a major criterium for further selection, because of its broad range of biological effects $(12,14)$. As a result of the screening for effects on both the alternative and classical pathways of activation, a very high rate of active plant extracts from the species tested was found. More than $60 \%$ of the number of aqueous plant extracts from 47 species tested showed activity, ranging from significant to very strong, on one or both pathways of complement activation in vitro. Some of these results are shown in Table 1.

Although only one active concentration is shown in Table 1, in fact a dose-dependent activity relation was found in all cases. The aqueous extracts of some plant species (e.g. Androghraphis paniculata, Asparagus falcata, Munronia pumila, Piper longum) selectively or predominantly inhibit the classical pathway of complement activation. Others (e.g. Aegle marmelos) influence the alternative pathway activation in particular. A third group of aqueous plant extracts (e.g. Azadirachta indica, Picrorhiza kurroa, Vernonia cinerea) display potent inhibitory activity on the activation of both pathways of complement. The aqueous extracts of some species (e.g. Cyclea burmanni) which show moderate activity on the complement pathways were found to be strongly active as a stimulator of MIF production of human lymphocytes. A full report of the screening studies will be published separately.

This paper focuses on results obtained in continued studies with fractions and isolated single compounds from the species Azadirachta indica, Woodfordia fruticosa, Picrorhiza kurroa, and Jatropha multifida.

\section{Azadirachta indica}

This species is a reputed medicinal plant in Sri Lanka and India. Several parts of the tree are used for preparations in Ayurveda and in other traditional systems of medicine. Biological and medical properties attributed to preparations of this plant in classical Sanskrit texts are for example:

- a bitter - very bitter taste [tikta, sutikta(ka)];

- it kills parasites [krmighna];

- has salutary properties [arista];

- suppression of disease [niyamana];

- drives away a certain group of skin diseases [kusthahan];

- drives away itches and inflamed wounds;

- it matures unmature swellings (inflammations);
- cleansing of mature inflamed wounds [vranam pakvam visodhayet].

In today's traditional uses, aqueous extracts (decoctions) and fermented potions (Nimba Arishta) prepared from bark material hold an important place. These preparations are used as tonics and against rheumatic conditions and various skin diseases $(19,20)$. In recent studies, a $75 \%$ methanol extract of the bark and leaves of Azadirachta indica was demonstrated to have an anti-inflammatory and antipyretic effect (21). Other authors have described polysaccharides from the bark to possess antitumor, interferon-inducing, and anti-inflammatory activities $(22,23)$.

In our experimentation with bark material, aqueous extracts were the starting point because in Ayurveda practice the preparations from this plant material are aqueous decoctions and fermented potions. The preliminary finding of strong inhibitory activity on complement activation led to an extension of the investigation. Besides complement inhibition, the effects of the aqueous extract on the respiratory burst by activated PMN leucocytes and production of the migration inhibition factor (MIF) was studied first (24). The results have been summarized in Table 2. Dose-dependent inhibitory effects have been established on both pathways of complement activation as well as on the production of oxygen radicals by activated PMN leucocytes. The inhibitory effect on the classical pathway of complement is much more pronounced than that on the alternative pathway. In addition, the aqueous extract was shown to increase the production of MIF, a lymphokine which in vivo attaches monocytes and macrophages to their site of action.

Table 2 Summarized modulative activity of the aqueous extract from the stem bark of Azadirachta indica (24).

\begin{tabular}{ll}
\hline Immune factor & $\begin{array}{l}\text { Modulatory effect of aqueous } \\
\text { bark extract of } A \text {. indica }\end{array}$ \\
\hline CP complement activation & Potent inhibition \\
AP complement activation & $\begin{array}{l}\text { Inhibition } \\
\text { PMN leucocytes activation }\end{array}$ \\
MIF production by lymphocytes & Stimulation
\end{tabular}

The inhibition of complement activation and the superoxide anion production by PMN leucocytes may be the in vitro correlate of the anti-inflammatory and antirheumatic effects claimed for the decoctions of Azadirachta indica bark in traditional medicine. On the other hand the stimulatory property of the aqueous extract on MIF production might be an underlying factor in the general stimulating and skin-healing properties of Azadirachta indica bark preparations in traditional practice. The activity-guided fractionation of the aqueous extract was performed on the basis of the anti-complementary action and the chemiluminescence inhibition. During these procedures it became clear that compounds with a macromolecular nature (non-dialysable) were mainly responsible for the activity on complement, whereas low $\mathrm{m}^{\mathrm{r}^{1}}$, ular (dıalysable) compounds displayed the inhibitor dctivity - PMN leucocytes. In fact two peptidoglycans NB-I nole:ul ass $>$ $150 \mathrm{kD}$ ) and NB-II (molecular mass $12 \mathrm{kD}$ ) wt. fou nd to te the major inhibitory compounds on complement activauvn, i able

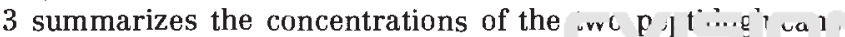
NB-I and NB-II, and the crude aqueous extrart of Azantirnento 
Table 3 Inhibitory concentrations of two peptidoglucans (NB-I and NB-II) from Azadirachta indica bark, and the crude aqueous extract (CAE) from the same bark material showing $50 \%$ inhibition $\left(\mathrm{Cl}_{50}\right)$ on the classical as well as the alternative pathway of complement activation.

\begin{tabular}{l|c|c}
\hline & \multicolumn{2}{c}{$\begin{array}{c}\text { Concentration showing } \mathrm{Cl}_{50} \text { (50\% inhibition) } \\
\text { CP }\end{array}$} \\
& (Classical Pathway) & $\begin{array}{c}\text { AP } \\
\text { (Alternative Pathway) }\end{array}$ \\
\hline CAE & $18 \mu \mathrm{g} / \mathrm{ml}$ & $311 \mu \mathrm{g} / \mathrm{ml}$ \\
NB-I & $42 \mu \mathrm{g} / \mathrm{ml}$ & $150 \mu \mathrm{g} / \mathrm{ml}$ \\
NB-II & $17 \mu \mathrm{g} / \mathrm{ml}$ & $75 \mu \mathrm{g} / \mathrm{ml}$ \\
\hline
\end{tabular}

indica bark which show $50 \%$ inhibition $\left(\mathrm{CI}_{50}\right)$ on the classical as well as the alternative pathway of complement.

The carbohydrate part of NB-II consists, besides glucose as major constituent, also of considerable amounts of galactose, arabinose, and mannose, and traces of xylose. However, the carbohydrate part of NB-I contains, besides glucose as major constituent, only minor traces of galactose and arabinose.

${ }^{13} \mathrm{C}-\mathrm{NMR}$ spectroscopy of NB-I and NB-II revealed the presence of glucose in a branched structure with $\alpha$ 1,$4 ; \alpha-1,6$; and possibly also 1,3 links. The protein parts of NB-I and NB-II constitute $5.5 \%$ and $9.8 \%$, respectively, of these active compounds. NB-I and NB-II are present in the crude aqueous extract of $A$. indica stem bark in concentrations of 10.6 and 4.0 weight $\%$, respectively (24).

The low molecular mass compounds which are responsible for the inhibition of oxygen radicals production by PMN leucocytes could be concentrated by eluotropic perforation of the methanol-soluble fraction of the crude aqueous extract of the stem bark. The active compounds were concentrated in the diethyl ether and ethyl acetate perforates. Subsequently the ether fraction was separated by HPLC into its constituents and their activity determined. Figs. 2 and 3 illustrate the relation between the separated compounds and their inhibition of the chemiluminescence generated by activated PMN leucocytes.
The active compounds isolated have been identified as gallic acid (fraction 4), (+)-gallocatechin (fraction $6),(+)$-catechin (fraction 10), and (-)-epicatechin (fraction 13). The total fraction of which these compounds constitute the major part is almost $2 \%$ of the aqueous extract of $A$. indica stem bark. In view of the potency of their action and their contents in the aqueous extract, their contribution to the total immunomodulatory effect has to be taken into serious account. The interference of these well-known naturally occurring compounds with PMN functions in the immune response is new and very interesting. Their phenolic nature and, in particular, their di- and trihydroxy-substitution pattern may prove to be of significance for the explanation of the mechanism of action. Preliminary studies with the fraction containing these compounds have shown that they do not interfere with the capacity of phagocytosis itself. Neither do they interfere with zymosan or its opsonized form as activating agent for PMN leucocytes (25).

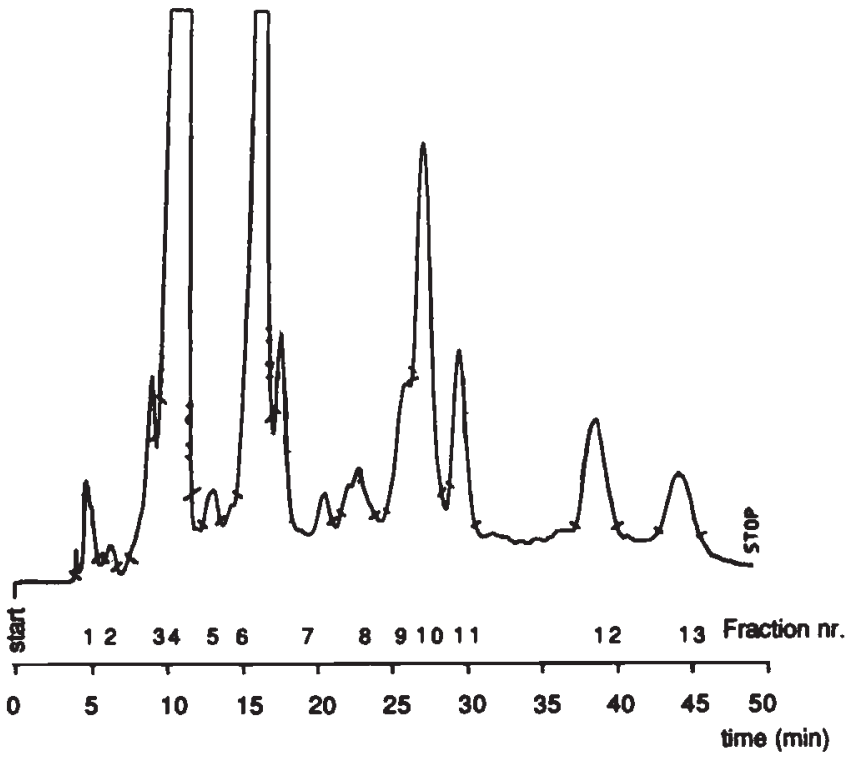

Fig. 2 HPLC of the diethyl ether fraction of Azadirachta indica bark.

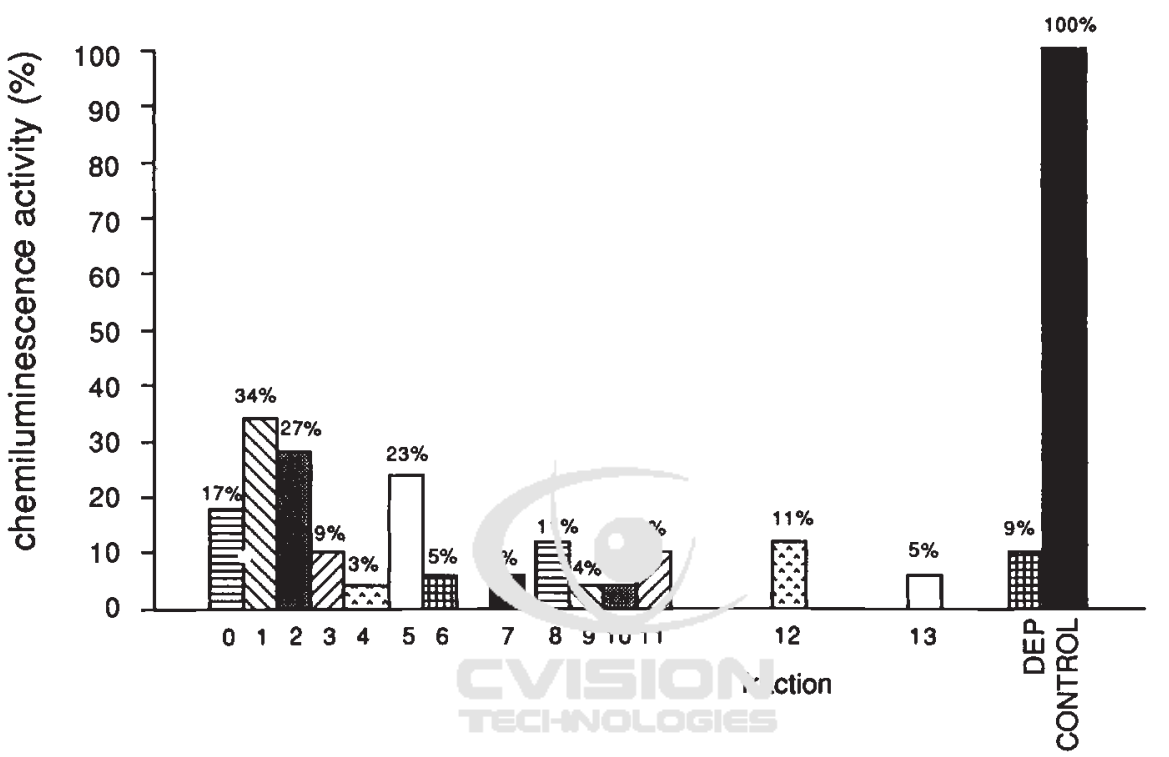

Fig. 3 Chemiluminescence of the fractions from Fig. 2. 


\section{Woodfordia fruticosa}

Research into the preparative aspects of traditional decoctions and fermentations manufactured from Azadirachta indica bark shed light on items which could be further rationalized. When decoctions of Azadirachta indica are fermented anaerobically according to traditional prescriptions, dried flowers of Woodfordia fruticosa are added in considerable proportions (3.2\%). Since the constituents and the fermentation products of this plant ingredient might influence the immune system as well, it was decided to include the flowers of this species in our study. Thorough evaluation of the technological and theoretical aspects of such preparations led us to study:

a) the consequences of prolonged aqueous extraction of Azadirachta bark material and the subjection of these extracts to anaerobic fermentations for the immunomodulative activity;

b) the role of Woodfordia fruticosa flowers in anaerobic fermentation procedures and the consequences of this addition for the immunomodulatory action of the preparation.

It was found that prolonged extraction with boiling water drops the anticomplementary activity of the resulting aqueous extract of Azadirachta bark. However, when a decoction of Azadirachta bark is subjected to anaerobic fermentation with yeast, its anticomplementary activity on the classical pathway does not change significantly. When flower material of Woodfordia fruticosa is added to an Azadirachta bark decoction, in the proportion used in the traditional preparation, the inhibitory activity on the classical pathway of complement is significantly enhanced. The potency of this immunomodulative activity is of the same order after having subjected the mixture to anaerobic fermentation with yeast.

A macerate of Woodfordia material alone displays potent inhibitory effects on both pathways of complement and on PMN leucocytes activation. After anaerobic fermentation a minor change takes place in anticomplementary activity, but the inhibition on PMN is considerably enhanced.

Table 4 illustrates the activities of Azadirachta bark extracts and Woodfordia flower extracts. The changes in chemiluminescence which takes place in Woodfordia flower extract during 28 days of anaerobic fermentation can at least partly be correlated with the formation of gallic acid. Fig. 4 illustrates the increase of gallic acid content in the fermentate. Fig. 5 shows the decrease of the $\mathrm{pH}$ and the increase of the UV absorbance at $259 \mathrm{~nm}$. In the same period of fermentation the inhibition of oxygen radical production by activated PMN is shown (Fig. 5) to be dramatically enhanced $\left(\mathrm{CI}_{50}\right.$ at about $800 \mathrm{ng} / \mathrm{ml}$ ). Since the chemiluminescence determinations were carried out in a much lower concentration range of the fermentate and with a $\mathrm{pH}$ adjusted to neutral, the enhancement of the chemimulinescence inhibition cannot be assigned to $\mathrm{pH}$ decrease but to the presence of gallic acid and other phenolic compounds. Gallic acid, a compound with . wiy low systemic toxicity, has been proved in these .udies tn be a potent inhibitor of neutrophil production of e oxyg n dicals. A gallic acid concentration of about $5 \mu \mathrm{g} / \mathrm{ml}$ 'reac'v linuured a $50 \%$ inhibition $\left(\mathrm{CI}_{50}\right)$ of free oxygen radical $\mu_{2}$. : nn sy $\mathrm{PMN}$ in

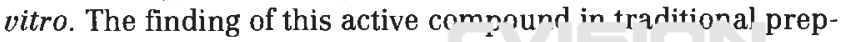

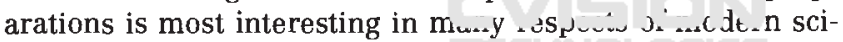

Table 4 Biological activities of aqueous extracts of Azadirachta indica bark and Woodfordia fruticosa flowers.

\begin{tabular}{lccc}
\hline & \multicolumn{3}{c}{$\mathrm{Cl}_{50}(\mu \mathrm{g} / \mathrm{ml})$} \\
\hline & $\begin{array}{c}\text { Complement activity } \\
\text { classical } \\
\text { pathway }\end{array}$ & $\begin{array}{c}\text { alternative } \\
\text { pathway }\end{array}$ & Chemiluminescence \\
& 7.5 & 145 & 30 \\
W. fruitcosa & 22 & 170 & 19 \\
A. indica & & & \\
\hline
\end{tabular}

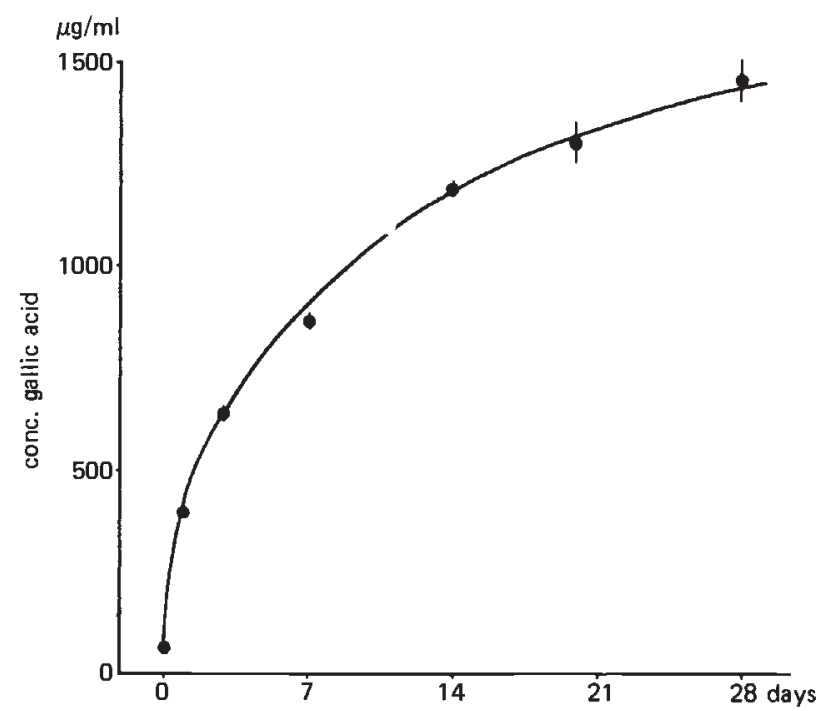

Fig.4 Time course of gallic acid content $(\mu \mathrm{g} / \mathrm{mll})$ during a fermentation process of Woodfordia fruticosa flowers.

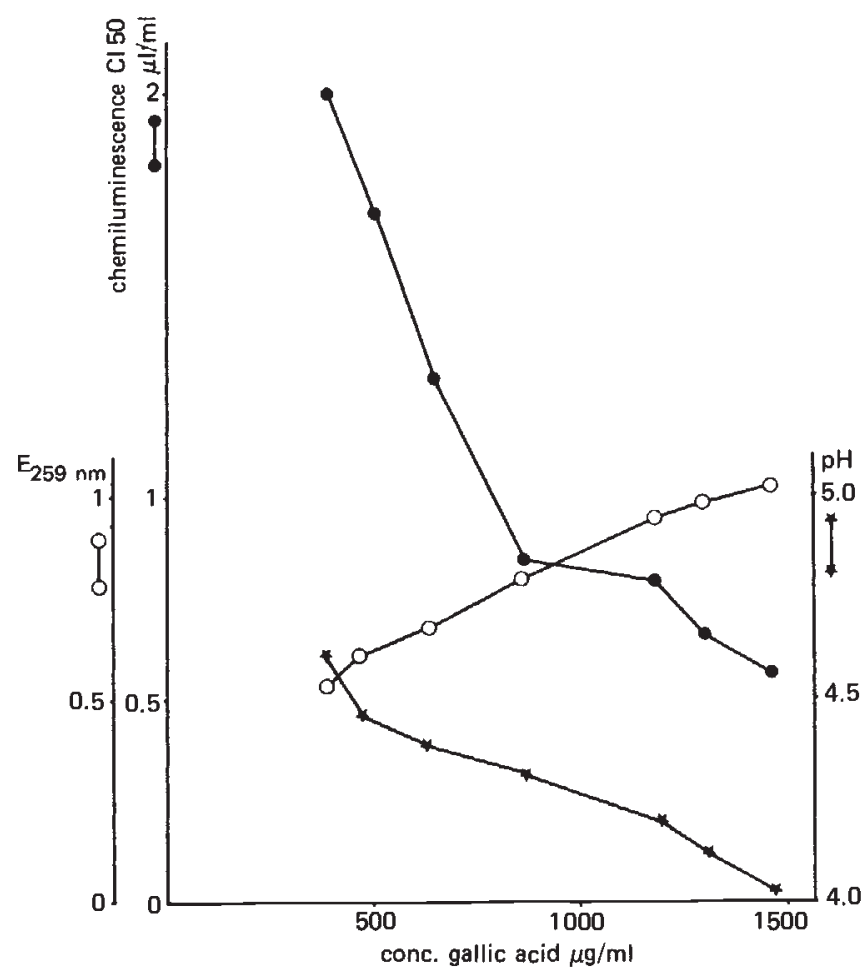

Fig. 5 UV259 absorption, $\mathrm{pH}$ and chemiluminescence $\mathrm{Cl}_{50}$-values of fermented extracts of Woodfordia fruticosa flowers, in relation to the gallic acid content of the fermentation broth. 
ence. Derivatives of gallic acid (e.g. propyl gallate) are currently being used as anti-oxidants in our foods.

The interest in the biological effects of gallic acid and its derivatives is reflected in many recent scientific studies $(26,27,28)$. It was shown for instance by Weinke et al. in 1987 that propyl gallate and octyl gallate inhibit ethylene formation from methional in NADPH-oxidizing rat liver microsomes (26). A free radical scavenging activity was assumed and the authors (26) concluded that these gallic acid antioxidants may possess a protective potential during chemically induced microsomal oxidations.

Another group of authors (Woll et al., 1987) recently described the blocking of high-conductance anion channels in membranes by gallic acid (27). Berger et al. in 1985 (28) found that TMB-8 [3,4,5-trimethoxybenzoic acid 8(diethylamino)octyl ester] strongly inhibits the release of $\mathrm{Ca}^{2+}$ from intracellular stores and completely blocks the receptor expression responses $\left(\mathrm{CR}_{1}\right.$ and $\left.\mathrm{CR}_{3}\right)$ on the surface of neutrophils. This is most interesting and suggestive for a similar role for gallic acid itself and related derivatives occurring in extracts and fermentates. The results of our experimentation with the flowers of Woodfordia fruticosa allow some conclusions so far:

- Constituents extracted from the flowers of this plant contribute substantially to the immunemodulatory acitivity in vitro of a traditional preparation (i.e. decoction) with Azadirachta indica bark extractives as main ingredient.

- After fermentation the most pronounced activity is expressed on activated PMN leucocytes, i.e. in terms of inhibition of oxygen radical production.

- This inhibitory activity is at least partly connected with the presence of gallic acid which is formed during fermentation (up to $0.15 \%$ in 28 days of anaerobic fermentation). More potently active phenolic compounds are also present in the fermentates.

- In pharmaceutical terms the presence of gallic acid in such a traditional Ayurveda preparation (Arishta) represents an early form of drug preservation (antioxidant).

- The potent inhibitory activity of gallic acid and related derivatives on PMN activation and other cellular mechanisms may prove in the future to be at the basis of claimed efficacy of fermented traditional potions (Arishtas) used in preventive and curative traditional medications.

\section{Picrorhiza kurroa}

The roots and rhizomes of this plant and its preparations are used to promote "blood purification", the drainage of morbid substances, in cases of liver, spleen, gastrointestinal, and bile disorders, against infections and inflammatory conditions. In Sri Lanka, some Ayurveda professionals consider Picrorhiza to be a special remedy against cough. It is used as a decoction.

In our preliminary screening studies for activity, aqueous extracts displayed n- - IIt inhivition on both pathways of complement activatir (T: ble ${ }^{1}$ The same extract also showed a significant stimu, ory of in the production of MIF. In continuation of these 1 . vilts activi $y$-guided fractionation of the crude extracts was perfonisu wased on the effects on

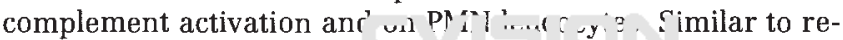
sults obtained with Azadircento incilco macromnlecular com- pounds from Picrorhiza kurroa were found to be responsible for the anticomplementary activity, and a fraction of low molecular mass compounds contained the active constituents responsible for the inhibition of free oxygen radicals from activated PMN leucocytes.

The most interesting anticomplementary polymer has been coded S1. It is methanol-soluble and is eluted from a Sephadex G-200 column within the void volume. S1 is selectively inhibitory on the classical pathway of complement $\left[\mathrm{CI}_{50}\right.$ is $\left.0.6 \mu \mathrm{g} / \mathrm{ml}\right]$. It is relatively stable as it retains its activity under extraction conditions with boiling water, but can also be extracted with cold water $\left(4^{\circ} \mathrm{C}\right.$ for $\left.24 \mathrm{~h}\right)$.

The polymer consists of $34 \%$ carbohydrates and $3 \%$ protein; it does not contain long-chain fatty acids and its contamination with bacterial LPS is negligble (29). The molecular mass of $\mathrm{S} 1$ is between $80-100 \mathrm{kD}$.

The fraction of low molecular mass compounds which show potent inhibition on activated PMN leucocytes was analysed by HPLC. The known constituents identified were picroside I, picroside II, vanillic acid, and apocynin. The structure formulae are shown in Fig. 6. Picroside III was only tentatively identified. In Table 5 , the concentrations of apocynin, picroside II, and vanillic acid showing $50 \%$ inhibition $\left(\mathrm{CI}_{50}\right)$ expressed in $\mu \mathrm{g} / \mathrm{ml}$ and micromoles are given. It can be seen that apocynin shows the strongest activity.

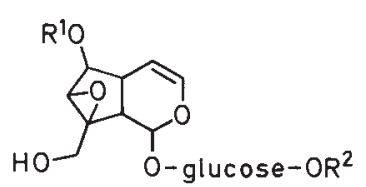

\begin{tabular}{|c|c|c|}
\hline & $R^{1}$ & $R^{2}$ \\
\hline picroside I & $\mathrm{H}$ & $-\underset{\Pi}{\mathrm{C}}-\mathrm{CH}=\mathrm{CH}-\longrightarrow$ \\
\hline picroside II & & $\mathrm{H}$ \\
\hline
\end{tabular}

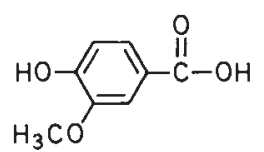

vanillic acid

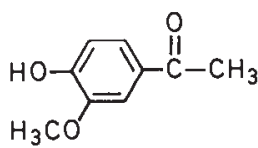

apocynin
Fig. 6 Structures of picrosides I and II, vanillic acid, and apocynin.

Table 5 Constituents from Picrorhiza kurroa roots showing inhibition of the production of free oxygen radicals by zymosan-activated PMN leucocytes. Micromolar and $\mu \mathrm{g} / \mathrm{ml}$ concentrations inducing $50 \%$ inhibition are given.

\begin{tabular}{l|c|c}
\hline Active compounds & \multicolumn{2}{c}{$\begin{array}{c}\text { Inhibitory concentrations showing } 50 \% \\
\text { of inhibition }\left(\mathrm{Cl}_{50}\right)\end{array}$} \\
& $\mu \mathrm{g} / \mathrm{ml}$ & $\mu \mathrm{Mol}$ \\
\hline Apocynin & 1 & 5 \\
Picroside II & 18 & 38 \\
Vanillic acid & 19 & 110 \\
\hline
\end{tabular}


The concentrations of picroside I needed to induce a $50 \%$ inhibition are about one thousand times higher than those of picroside II. The potent activity of apocynin as a relatively simple molecule is very interesting. Its ortho-oxygenated substitution is suggested to be the basis of its interference with the production of oxygen radicals by leucocytes. The mechanism of action is being studied. A scavenger effect has been ruled out and the inhibition seems to be on another mechanistic level.

\section{Jatropha multifida}

The latex of this plant is used for the treatment of wounds and skin infections in folkloric medicine in Indonesia and several other Asian countries (30-32). The latex was collected from the leaf stalk in intervals of two weeks at 5 a.m. during a period between March and September. The harvested latex was kept frozen at $-20^{\circ} \mathrm{C}$ until use.

Guided by activity on complement activation, several compounds with potent inhibitory in vitro effects were isolated and identified. This paper reports on two novel compounds called multifidol and multifidol- $\beta$-D-glucopyranoside (Fig. 7). Their structure elucidation is reported (33). Multifidol is (2-methylbutyryl)-phloroglucinol. Both compounds, multifidol and its $O$-glucoside, irmibit the classical pathway of complement activation in vitro. Fig. 8 illustrates the relation between the log concentration in $\mu \mathrm{g} / \mathrm{ml}$ of these compounds and their effects on the classical pathway expressed in absorbance at $\mathrm{E} 405 \mathrm{~nm}$ of the test solution. Multifidol effects a practically complete inhibition of complement at a concentration of $62.5 \mathrm{mg} / \mathrm{ml}$. Multifidol glucoside shows a $100 \%$ inhibition at a much higher concentration, i.e. $490 \mu \mathrm{g} / \mathrm{ml}$. At much higher concentrations $(<245 \mu \mathrm{g} / \mathrm{ml})$ than those which show inhibition of complement, multifidol induces a hemolytic phenomenon on the target cells (erythrocytes) in this assay. This phenomenon was not found in the case of the glucosidic form.

Fig. 9 illustrates the activities of multifidol and multifidol glucoside on the production of oxygen radicals by activated PMN leucocytes. It can be seen from this figure that at a concentration of $15.6 \mu \mathrm{g} / \mathrm{ml}$ multifidol and multifidol glucoside still show inhibitory activities of $55 \%$ and $23 \%$, respectively. The structures of these phenolic compounds are not only interesting as new Euphorbiaceae constituents but also in relation to their immunomodulatory activity. In contrast to the $o$ dihydroxy and the gallo-trihydroxy phenolic compounds which we normally find actively interfering with the mechanisms of oxygen radical production of leucocytes, multifidol and its $O$ glucoside represent examples of a phloroglucinic nucleus. However, the methylbutyryl group with the keto function adjacent to the one of phloroglucin-OH groups may be of importance for the activity. Further studies are in progress.

\section{Concluding Remarks}

It has been shown that an ethnopharmacognostic approach in the search for immunomodulators can be fruitful.

This approach leads to novel compounds as well as known compounds of which their biological activity and therapeutic value still awaits exploration and elaboration.<smiles>C#CCC(C)C(=O)c1c(O)cc(O)cc1O</smiles>

multifid ol

[(2-methylbu tyryl)-phloroglucinol]

Fig. 7 Structures of multifidol and its $O$-glucoside.

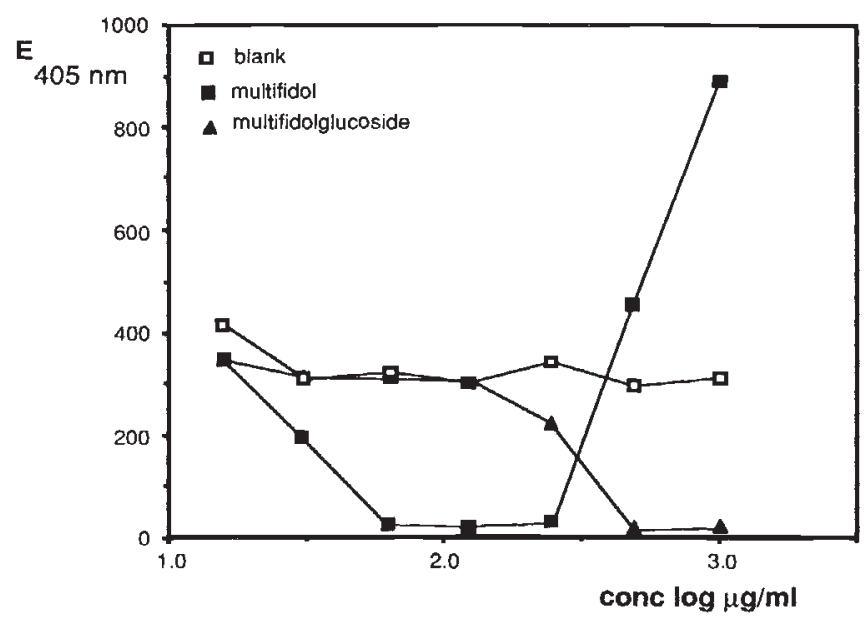

Fig.8 CP complement activity of multifidol and its $O$-glucoside.

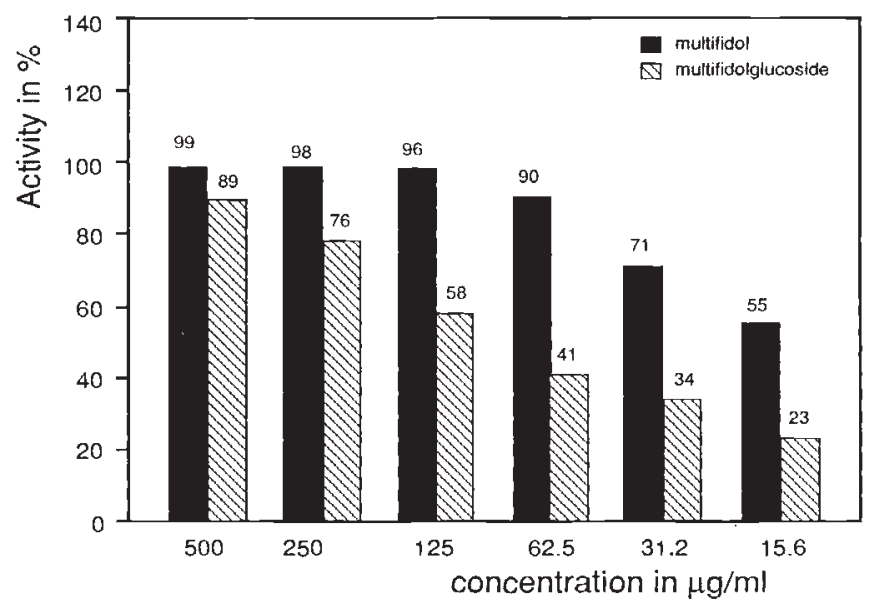

Fig.9 Chemiluminescence activity of multifidol and its $O$-glucoside. 
An ethnopharmacognostic approach represents a basic methodology to explore empirical and traditional knowledge and practices of medical and health systems.

Both traditional medical and health systems and modern medical science and health care may benefit from such studies.

It should be understood that fruitful ethnopharmacognostic research is only possible when researchers are equipped with a functional knowledge of chemotaxonomy, the distribution of compound classes in the plant kingdom, biosynthetical relations and pathways, phytochemical methodology, biological, pharmacological and therapeutical actions of biogenic compounds, and pathogenic processes.

A prerequisite for ethnopharmacognostic research is a critical but an unprejudiced attitude

\section{Acknowledgements}

The investigations on Sri Lankan plant material and on Jatropha multifida were carried out with financial support from the Netherlands Ministry for Development Cooperation and Biohorma Beheer B. V., Elburg, The Netherlands, respectively. The authors gratefully acknowledge these supports. Dr. G. Jan Meulenbeld is gratefully acknowledged for the authorative translations of Sanskrit texts on Ayurveda.

\section{References}

1 Mechoulam, R. (1986) Cannabinoids as therapeutic agents, CRC Press, Inc. Bocoa Raton, Florida, USA.

2 Schultes, R. E. (1972) The future of plants as sources of new biodynamic compounds, in: Plants in the development of modern medicine (Swain, T., ed.), pp. 103-124, Harvard University Press, Cambridge, Mass., USA.

${ }^{3}$ Bruhn, J. G., Holmstedt, B. (1980) Ethnopharmacology: Objectives, principles and perspectives, in: Natural Products as Medicinal Agents (Beal, J. L. Reinhard, E., eds.), pp. 405-430, Hippokrates Verlag, Stuttgart.

${ }^{4}$ Holmstedt, B., Bruhn, J. G. (1982) Trends in Pharmacological Sciences 3, $181-183$.

5 Holmstedt, B., Bruhn, J. G. (1983) J. Ethnopharmacol. 8, 251-256.

${ }^{6}$ Labadie, R. P. (1986) J. Ethnopharmacol. 15, 221-230.

7 Elisabetsky, E., Setzer, R. (1986) Caboclo concepts of disease, diagnosis and therapy: Implications for ethnopharmacology and health systems in Amazonia, in: The Amazon Caboclo - Historical and Contemporary Perspectives (Parker, E. P., ed.), pp. 243-278, Studies of the Third World Societies, Publication No. 32, Williamsburg.

${ }^{8}$ Elisabetsky, E. (1986) J. Ethnobiol. 6, 121-128.

9 Cotman, C. W. Brinton, R. E., Galaburda, A., McEwen, B. Schneider, D. M. (1987) The Neuro-Immune-Endocrine Connection, Raven Press, New York, USA.

10 Ranade, S., Sathaye, B. V. (1985) The Fundamental Principles of Ayurveda, Willy Kremling, Kleinbittersdorf, West Germany.

11 Hood, L. E., Weissman, I. L., Wood, W. B., Wilson, J. H. (1984) Immunology, The Benjamin/Cummings Publishing Company Inc., Menlo Park, California, USA

12 Brown, E. J., Frank, M. M. (1981) Immunology Today 2, 129-134.

13 Roitt, I., Brostoff, J., Male, D. (1985) Immunology, Churchill Livingstone, Edinburgh/Gower Medical Publishing, London, U.K.

14 Goldstein, I. M. (1980) Complement in Infectious Diseases, Current Concepts, A scope publication, The Upjohn Company.

15 Klerx, J. P. A. M., Beukelman, C. J., van Dijk, H., Willers, J. M. N. (1983) J. Immunol. Methods 63, 215-220.

16 Feher, J., Csomos, G., Vereckei, A. (1987) Free Radical Reactions in Medicine, Springer-Verlag, Berlin.

17 Van der Nat, J. M., Klerx, J. P. A. M., van Dijk, H., De Silva, K. T. D. Labadie, R. P. (1987) J. Ethnopharmacol. 19, 125-131.

18 't Hart, L. A., van Enckevort, P. H., van Dijk, H., Zaat, R., De Silva, K. T. D., Labadie, R. P. (1988) J. Ethnopharmacol. 23, 61-71.

19 Ayurveda Pharmacopoeia, Vols. 1 and 2 (1979) Dept. of Ayurveda, Colombo, Sri Lanka, Vol. 1, p. 256; Vol. 2, pp. 268-269.

20 Dastur, J. F. (1977) Medicinal Plants of India and Pakistan, D. B. Taraporevala Sons \& Co., Bombay, India, pp. 29-31.

21 Okpanyi, S. N., Ezeukwu, G. C. (1981) Planta Med. 41, 34-39.

22 Fujiwara, T., Takeda, T., Ogihara, Y., Shimizu, M., Nomura, T., Tomita, Y. (1982) Chem. Pharm. Bull., 30, 4025-4030.

23 Terumo Corporation Patent (1983) Chem. Abstracts 100, 91350n Terumo Corporation Patent (1985) Chem. Abstracts 103, 11440q.

24 Van der Nat, J. M., 't Hart, L. A., van der Sluis, W. G., van Dijk, H., van den Berg, A. J. J., De Silva, K. T. D., Labadie, R. P. (1988) J. Ethnopharmacol., submitted.

25 Van der Nat, J. M., van der Sluis, W. G., 't Hart, L. A., van Dijk, H., De Silva, K. T. D., Labadie, R. P. (1989), Planta Med., submitted.

26 Weinke, S., Kahl, R., Kappus, H. (1987) Toxicological Lett. 35, $247-$ 251.

${ }_{27}$ Woll, K. H., Leibowitz, M. D., Neurncke, B., Hille, B. (1987) Pflugers Arch. 410, 632-640.

28 Berger, M., Birx, D. L., Wetzler, E. M., O'Shea, J. J., Brown, E. J., Cross, A. S. (1985) J. Immunol. 135, 1342-1348.

29 Simons, J. M., 't Hart, L. A., van Dijk, H., Fischer, F. C., De Silva, K. T. D., Labadie, R. P. (1989) J. Ethnopharmacol., in press.

30 Heyne, K. (1950) De nuttige planten van Indonesie, p. 938, N. V. Uitgeverij van Hoeve, 's Gravenhage, Brandung.

31 Quisumbing, E. (1978) Medicinal plants of the Philippines, pp. $517-$ 518, Katha Publishing Company, Manila, The Philippines.

32 Pancho, J. V. (1983) Philippine Journal of Biology 12, 193-284.

33 Kosasi, S., van der Sluis, W. G., Labadie, R. P. (1989) Phytochemistry, in press. 